\title{
SEISMIC BEHAVIOR OF BOLTED CONNECTIONS WITH SLOT BOLT HOLES AT AMBIENT AND ELEVATED TEMPERATURE
}

\author{
Z.X. Hou ${ }^{1}$, C. Gong ${ }^{2}$, Y. Zhang ${ }^{1,5}$, Y.Z. Sun $^{1}$, J. Jiang ${ }^{1,3,{ }^{*}}$ and G.Q. Li ${ }^{1,4}$ \\ ${ }^{1}$ College of Civil Engineering, Tongji University, Shanghai 200092, China \\ ${ }^{2}$ Central Research Institute of Building and Construction Co.,Ltd, Beijing 100088, China \\ ${ }^{3}$ Engineering Laboratory, National Institute of Standards and Technology, MD 20899-8611, USA \\ ${ }^{4}$ State Key Laboratory for Disaster Reduction in Civil Engineering,Tongji University, Shanghai 200092, China \\ ${ }^{5}$ Department of Building Engineering, Logistics University of PAPF, Tianjin 300309, China \\ *(Corresponding author: Email: jiangjian_0131@163.com)
}

Received: 6 March 2017; Revised: 30 October 2017; Accepted: 25 November 2017

\begin{abstract}
This paper experimentally studies the seismic behavior of high strength bolted connections with slot bolt holes at ambient and elevated temperatures. A total of 6 specimens varying in bolt diameters, pretensions, temperatures are designed and tested. The results show that the connections with slot holes at both ambient and elevated temperatures have good energy dissipation capacity. It is found that connections with M30 bolts have better energy dissipation capacity and load-bearing capacity than those with M20 bolts, due to the larger friction force and sliding distance in M30 bolts since they have a larger pretention and wider slot hole. The sliding forces of the connections decrease with the increase of the number of loops. The sliding force decrease by about $50 \%$ after 60 loops at elevated temperatures, compared with $35 \%$ at ambient temperature. While the ultimate bearing capacity of the connections does not decrease much. The friction coefficient and area of hysteresis curves decrease in a similar trend by about $40 \%$ after the first 30 loops. After 60 loops, they are reduced to $40 \%$ and $50 \%$ of their initial values for the connections with M20 bolts and M30 bolts, respectively. The experimental results indicate the potential application of the connections with slot bolt holes for a dual-function component in a structure to simultaneously provide stiffness and energy dissipation capacity.
\end{abstract}

Keywords: Experiment, bolted connection, slot hole, seismic behavior, elevated temperature, sliding force, energy dissipation capacity

DOI: $10.18057 /$ IJASC.2018.14.8

\section{INTRODUCTION}

Historically, most major structural failures of steel structures in earthquake have been due to some form of connection failure [1]. A large amount of brittle failures of connections were observed in the Northridge earthquake in 1994 [2] which was due to their limited plastic deformation capacity. In the Kobe earthquake in 1995, a total of 988 steel constructions were damaged most of which were due to the brittle failure of beam-column joints. In addition, connections account for more than half the cost of structural steelwork, and their design and detailing are therefore of primary importance for the safety and economy of structures.

It is found to be difficult to generate sufficient ductility of welded connections even if the welding quality is ensured by removing beam column welding lining board [3-5]. As an alternative, connections with high strength bolts are a preferred method of connecting members on the site [6]. The standard circular bolt holes would become elliptical holes under cyclic loads, leading to a reduction in their energy consumption capacity [7]. To address the issues for connections with standard holes such as demand of high installation accuracy, limited energy dissipation capacity, decreased load-bearing capacity when deforming to an elliptical shape, slot bolt holes have been applied. Astaneh-Asl [8] proposed to allow high-strength bolting joints to slip under strong earthquake. The friction between the interfaces and the extrusion of hole wall consumed the 
earthquake energy to avoid the brittle failure or collapse of structures. Grigorian [9] designed the long elliptical slot bolt holes. The slot was parallel to the force direction of members. When the tensile force in a connection was more than the static friction force between the friction surfaces, the connection would slide to consume energy. This kind of connections could also be used for a single support or beam-column connections in steel frames [10-12] to improve the ductility of the joints and avoid brittle failure at the joints. Peng et al. [13] explored the relationship between the opening area of the high strength bolt connection and the pretension loss, the friction coefficient, respectively, and gave the suggested value of the hole shape coefficient. ANSI/AISC360-10 [14] and European standard (EC3) [15] also provide the hole shape coefficient according to different hole shape. The length of the short axis of slot holes equals to the diameter of the corresponding standard hole, while the long axis is 1.7 times as long as the short axis. They also provide corresponding provisions in the case of different bolt hole spacing and margins. Compared to standard-hole connections, the installation of slot-hole connections is more convenient and cost-effective since it requires less machining precision [16].

While steel structures are not inherently fire resistant because much of the strength of steel will be lost when its temperature reaches $600^{\circ} \mathrm{C}$ or above during a fire. In addition, the large thermal conductivity of steel leads to a quick temperature rise in unprotected steel members of $600^{\circ} \mathrm{C}$ in $15 \mathrm{~min}$ [17]. As an essential component of steel structures, the behavior of connections under fire conditions plays a key role in the global stability of structures against collapse. Yang et al. [18] and $\mathrm{Yu}$ [19] investigated the anti-sliding capacity of high strength bolts at elevated temperatures. They found that the anti-sliding capacity of the connection increased as the temperature increased for temperatures below $400^{\circ} \mathrm{C}$.

The seismic or fire behaviour of steel connections have been investigated extensively but separately. The coupled effect of seismic and fire loads on the performance of steel connections is not well studied and understood. Recently, many efforts have been made for investigating the behaviour of structures subjected to post-earthquake fire [20-24]. The earthquake-induced damage in the structural members are considered in the following structural analysis of structures exposed to fire. However, there is few research on steel beam-to-column connections with slot bolt holes subjected to extreme hazards.

In contrast to the extensive studies on the behavior of structures under post-earthquake fire, there is a lack of research on the post-fire seismic behavior of structures. This is a realistic event for the successive earthquakes or secondary earthquakes, considering that the previous earthquake may cause the ignition of fire. This paper experimentally studied the seismic behavior of high strength bolted connections with slot holes at ambient and elevated temperatures. A total of six specimens with M20 and M30 bolts were designed and tested. The results of force-displacement curves and energy dissipation capacity were output and compared.

\section{TEST LAYOUT}

\subsection{Design of Specimens}

For traditional bolted connections between steel beams and columns, the bottom flange of the beam is bolted connected to the corbel which is welded to the flange of the column, as shown in Figure 1. To avoid the local buckling of the corbel and beam web, the key part of the bolted connection was selected to be tested in this study. A total of 6 specimens with sandblasting surfaces were designed, as listed in Table 1 and Figure 2. They were tested at ambient temperature $\left(20^{\circ} \mathrm{C}\right)$ and elevated temperature $\left(130^{\circ} \mathrm{C}\right)$ temperatures, respectively. The low temperature of the heated specimens was 
to consider the fire protection of steel beam-to-column connections as well as the thermal shielding effect at the connections (where many components in a relatively small space). The tested specimens were divided into two groups (S1 and S2) by varying the diameter of bolts and pretension forces. The diameters of M20 and M30 bolts are $20 \mathrm{~mm}$ and $30 \mathrm{~mm}$, respectively. The grade 10.9 high strength bolts were used with a tensile strength of $1000 \mathrm{MPa}$ and yield to tensile strength ratio of 0.9 . The Young's modulus of the bolts was 200GPa. The measured elongation of bolts was $15 \%$. The slot bolt holes were used for the corbel plate and their dimensions are shown in Figure 3. The holes were parallel to the axis of the beam. The maximum slip of the M20 and M30 bolt holes were $8.5 \mathrm{~mm}$ and $12.5 \mathrm{~mm}$, respectively. Figure 4 shows a specimen in the test. In order to prevent the local buckling of the specimen under compression, stiffening ribs were added on the corbel plate and part of the web of the beam was kept.

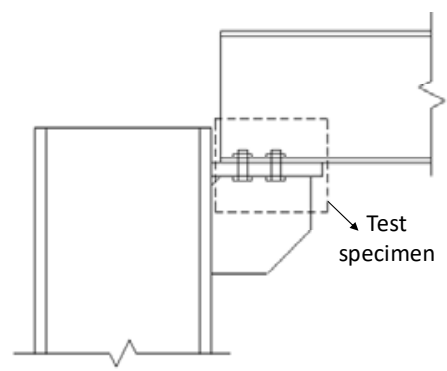

Figure 1. Schematic of Steel Beam-column Connection

Table 1. List of the Tested Specimens

\begin{tabular}{|c|c|c|c|c|}
\hline Test No. & Type of Bolts & $\begin{array}{c}\text { Temperature of } \\
\text { specimens } \\
\left({ }^{\circ} \mathrm{C}\right)\end{array}$ & $\begin{array}{c}\text { Type of } \\
\text { holes }\end{array}$ & $\begin{array}{c}\text { Pretension } \\
(\mathrm{kN})\end{array}$ \\
\hline S1-1 & M20 & 20 or 130 & slot & 143 \\
\hline S1-2 & M20 & 20 or 130 & slot & 140 \\
\hline S1-3 & M20 & 20 or 130 & slot & 152 \\
\hline S2-1 & M30 & 20 or 130 & slot & 337 \\
\hline S2-2 & M30 & 20 or 130 & slot & 316 \\
\hline S2-3 & M30 & 20 or 130 & slot & 354 \\
\hline
\end{tabular}
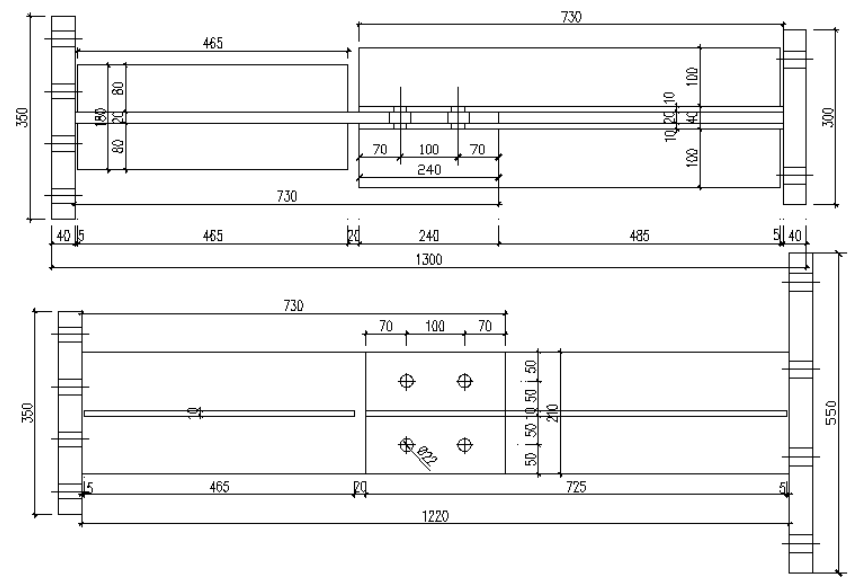

(a) S1 (M20 bolts) 

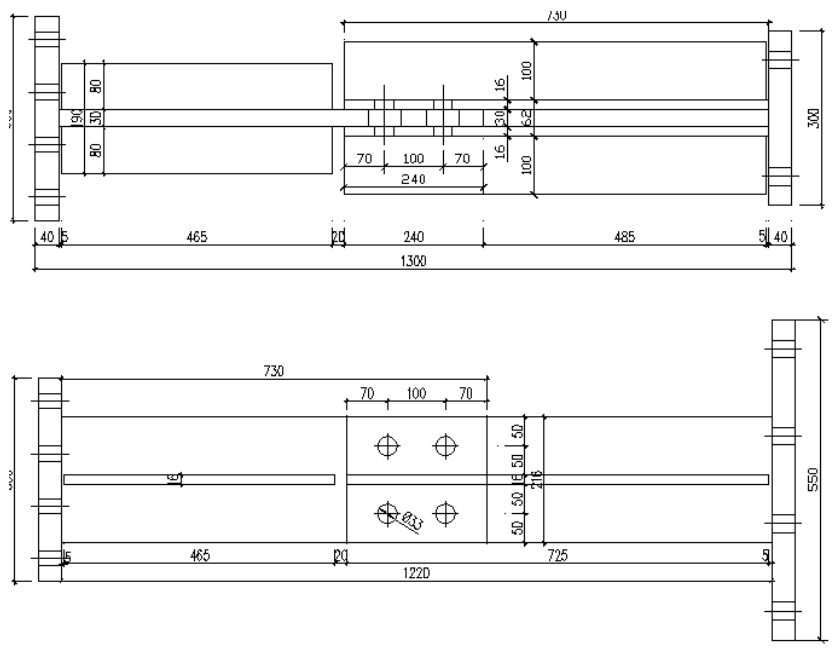

(b) S2 (M30 bolts)

Figure 2. Dimensions of the Specimens

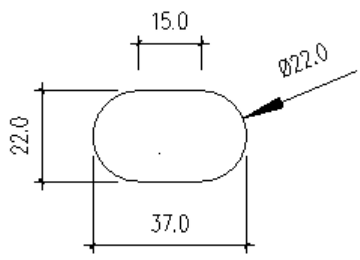

(a) M20

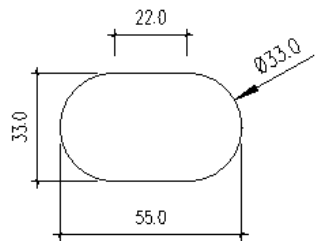

(b) M30

Figure 3. Dimensions of the Slot Bolt Holes on the Corbel Plate

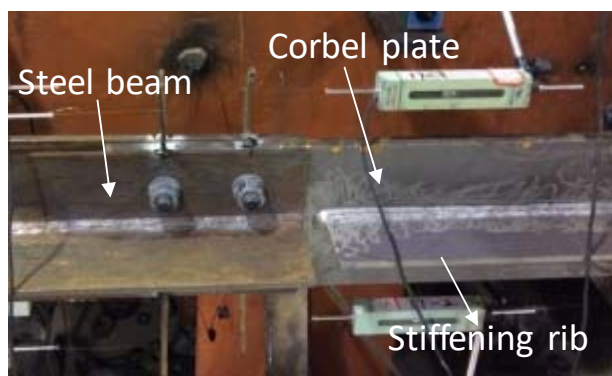

Figure 4. A specimen in the Test

\subsection{Pretension}

All the bolts were tightened before the tests by applying pretensions based on JGJ82-2011 and GB50205-2001. There are two means to impose tensile forces in the bolt: torque method and angle method. The former tightens the bolt by applying a torsion on the nut and the latter is to apply a relative angle between the nut and shank of the bolt. The torque method was used in the tests as it was simple and convenient to use. The pretension process was divided into initial and final twists based on a Chinese code (JGJ82-2011). An initial torque of half the ultimate torque was applied in the initial twist. The initial and final twists were completed within 24 hours. The ultimate torque of high strength bolts can be calculated by Eq. 1 .

$T_{c}=k \times P_{c} \times d$ 
where $T_{C}$ is the ultimate torque, in $\mathrm{N} \cdot \mathrm{m} ; k$ is the average value of the torque coefficient of the bolt connecting pair which is determined by experiments; $P_{c}$ is the pretension in the high strength bolt, in $\mathrm{kN}$, which can be determined by Table 3.2.5 of the design code JGJ82-2011. The design pretensions of M20 and M30 bolts were calculated as $155 \mathrm{kN}$ and $355 \mathrm{kN}$, respectively, according to the grade (10.9) and diameter of the bolts; $d$ is the diameter of the bolt screw, in $\mathrm{mm}$.

It is required that the applied pretension of bolts in practice should fall in the range of $0.95 \sim 1.05 P_{c}$. During the twist, the bolt pretension was measured by the strain gauge, as shown in Figure 5. High temperature strain gauges were used and arranged in the two grooves made on the symmetrical positons of the shank below the nut. The data wires of the strain gauges passed through the holes predrilled in the nut. The measured pretensions of bolts satisfied the requirement of maximum error of $5 \% P_{c}$.

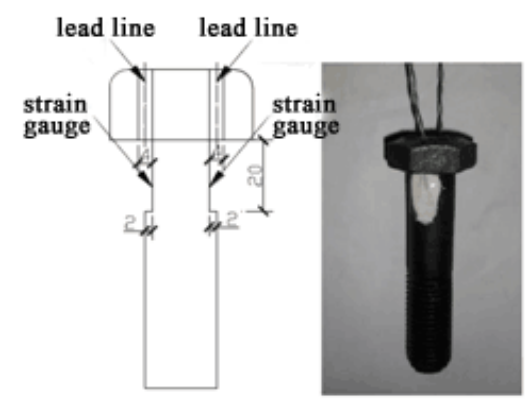

Figure 5. Arrangement of Strain Gauges on the Bolt

\subsection{Measurement}

An electric furnace was used to heat the specimens up to $200^{\circ} \mathrm{C}$, as shown in Figure 6 . The furnace has a heating capacity of $20^{\circ} \mathrm{C} \sim 1200^{\circ} \mathrm{C}$ and a maximum heating rate of $15 \mathrm{~kW}$. It consisted of two heating panels and concrete insulation panels at the two ends. The temperature inside the furnace was monitored by $2 \mathrm{~K}$-type thermocouples and the average temperature of these two measurements was calculated and used as the gas temperature in the furnace. Four $\mathrm{K}$ type thermocouples were arranged at the upper part, the middle part and the lower part of the specimens, respectively, to monitor its temperature, as shown in Figure 7. The deformation of the connections was measured by two symmetrically placed extensometers (Figure 8 ).
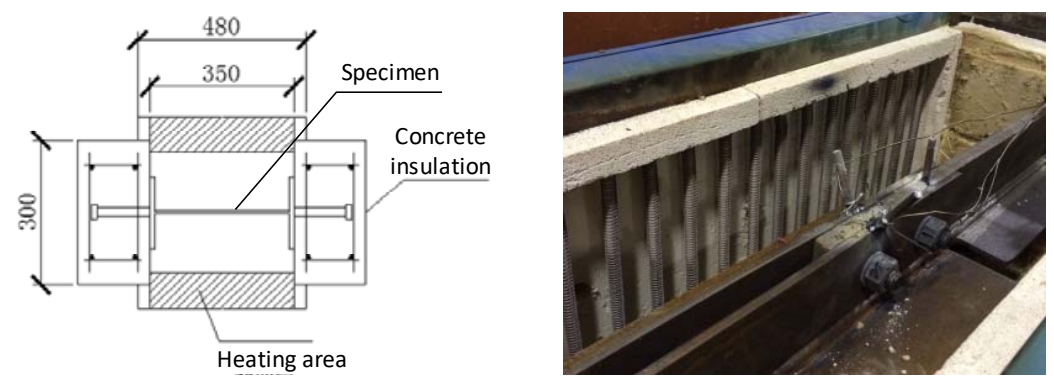

Figure 6. Specimens in the Electronic Furnace (All Units are mm) 


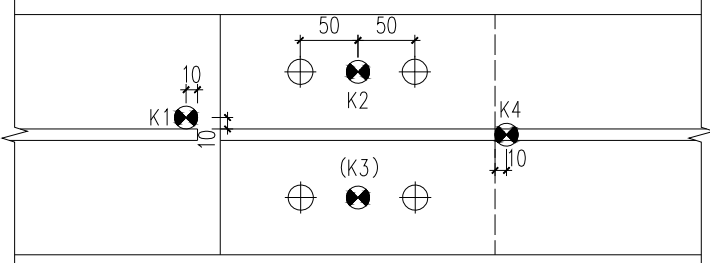

Figure 7. Arrangement of the Thermocouples

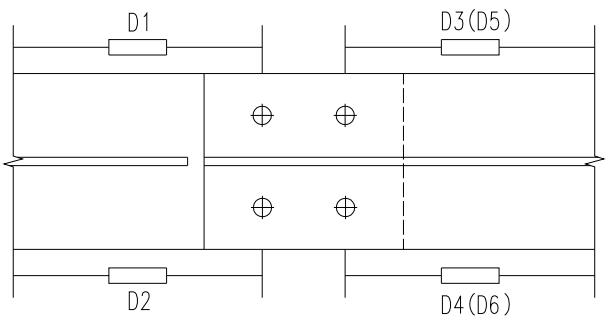

(a) Plan view

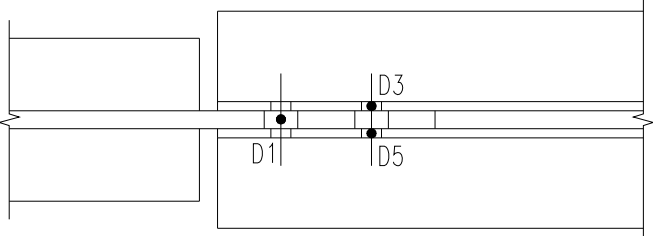

(b) Elevation view

Figure 8. Layout of Displacement Measurements

\subsection{Loading}

The specimens were firstly heated in the furnace (Figure 6) with a heating rate of $4 \sim 5^{\circ} \mathrm{C} / \mathrm{min}$ until reaching the target temperature of $130^{\circ} \mathrm{C}$. When the target temperature was reached, it remained for at least $30 \mathrm{~min}$ to guarantee the temperature of the component was constant and stable.

Loads were imposed based on Chinese codes GB50205-2001 and JGJ 101-96, as shown in Figure 9. At the beginning of the tests, force control was adopted until the load increased up to $10 \%$ of the slip load. The loading was held for $1 \mathrm{~min}$, after which it was applied smoothly in a speed of $3 \sim 5 \mathrm{kN} / \mathrm{s}$ until the occurrence of sliding of the connection. The displacement control was then adopted in an interval of $1 \mathrm{~mm}$ until the bolt was in contact with the hole. For each displacement level, three cyclic loadings were conducted. Once the bolt shank contacted against the hole wall, a cyclic loading of 60 loops was conducted to study the low cycle fatigue performance and energy dissipation capacity of the bolted connections with slot bolt holes.

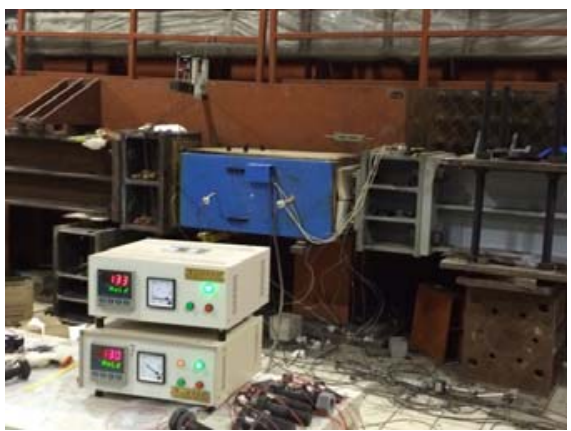

Figure 9. Loading of the Specimens 


\section{TEST RESULTS}

In the initial stage of loading, the specimens were in elastic stage. The relative displacement of the connections increased with the increase of the load, and the connections did not make a sound. When the load reached the sliding load, there was a loud noise, and the members experienced a first slide. A further loading on the connections led to gradual sliding accompanied by successive noises. For the latter cyclic loading stage, the connections in the first half of the loading process, issued a continuous ringing sound. The sound gradually declined until the loading was completed.

\subsection{Load vs Relative Displacement Curves of Specimens}

A comparison of force-displacement curves of the specimens $\mathrm{S} 1$ and $\mathrm{S} 2$ at $20^{\circ} \mathrm{C}$ and $130^{\circ} \mathrm{C}$ is shown in Figures 10 and 11, respectively. In general, the hysteresis loops of experiments at $130^{\circ} \mathrm{C}$ were similar to them at normal temperature. The seismic behaviour specimens at different temperatures shows the following common features as:

(1) The force-displacement curves were linear before the occurrence of bolt sliding in each loop. After the sliding, the stiffness of the connections degenerated rapidly, leading to a large increment of displacement as the force kept stable. The hysteresis curves were stretched as the loops of loading increased, and the area of the hysteresis loops increased greatly.

(2) As the number of loops increased, the sliding force decreased and the hysteresis curves had a slight tendency of pinching. This tendency occurred for both M20 and M30 bolts.

(3) The ultimate load-bearing capacity of the connections did not decrease much with the increasing loops of hysteresis loops.

(4) The hysteresis curves were symmetrical, and the middle part of the sliding section were rectangular and full. This indicated the significant energy dissipation capacity of bolted connections with slot bolt holes.

(5) Compared with the hysteresis loops of M20 bolts, those of M30 bolts were more full and the pinch phenomena were less obvious. This is due to the larger pretention and wider slot hole for M30 bolts compared to M20 bolts, leading to larger friction forces and sliding distances. This indicated that the slot holes of M30 bolts had a better seismic performance.

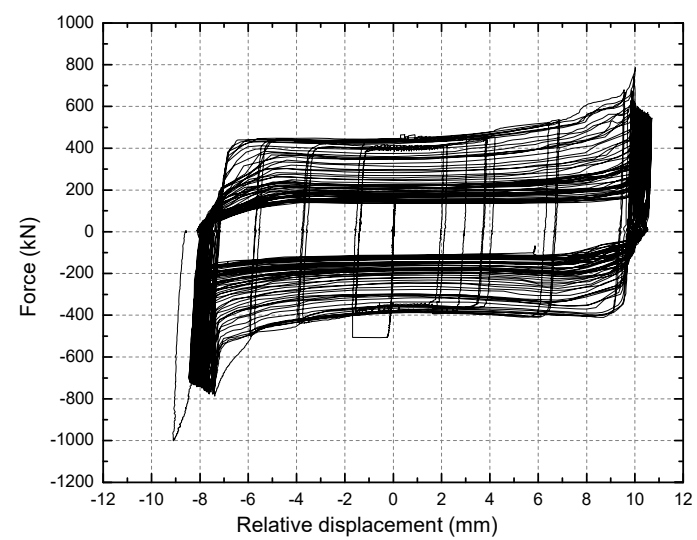

(a) $\mathrm{S} 1-1\left(20^{\circ} \mathrm{C}\right)$

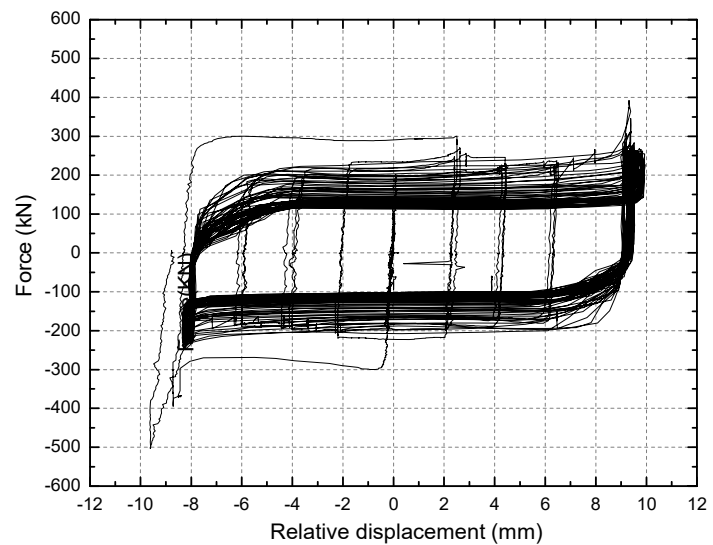

(b) $\mathrm{S} 1-1\left(130^{\circ} \mathrm{C}\right)$ 


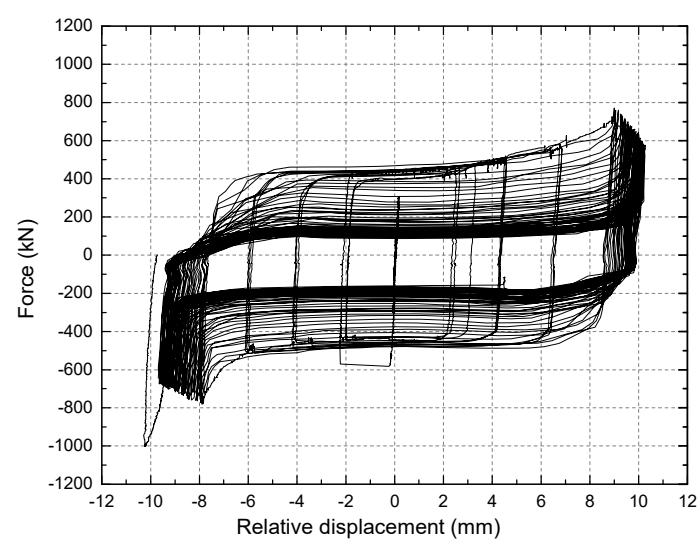

(c) $\mathrm{S} 1-2\left(20^{\circ} \mathrm{C}\right)$

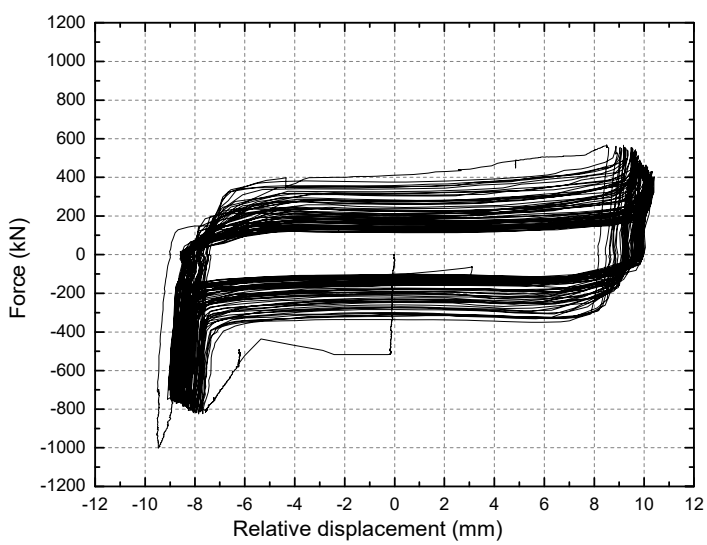

(e) $\mathrm{S} 1-3\left(20^{\circ} \mathrm{C}\right)$

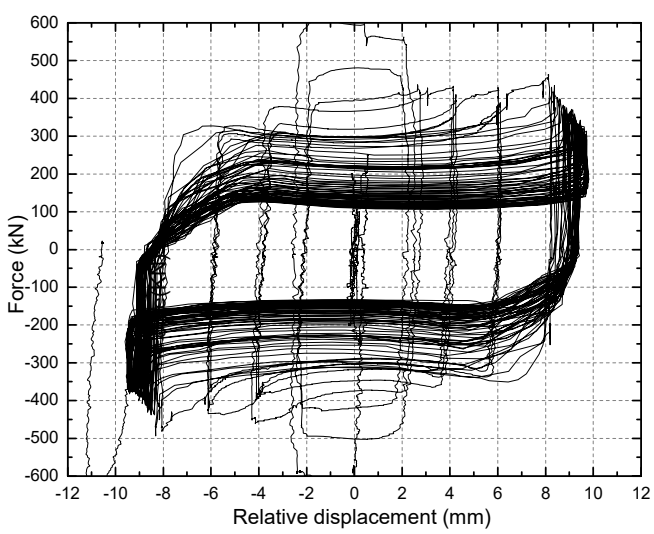

(d) $\mathrm{S} 1-2\left(130^{\circ} \mathrm{C}\right)$

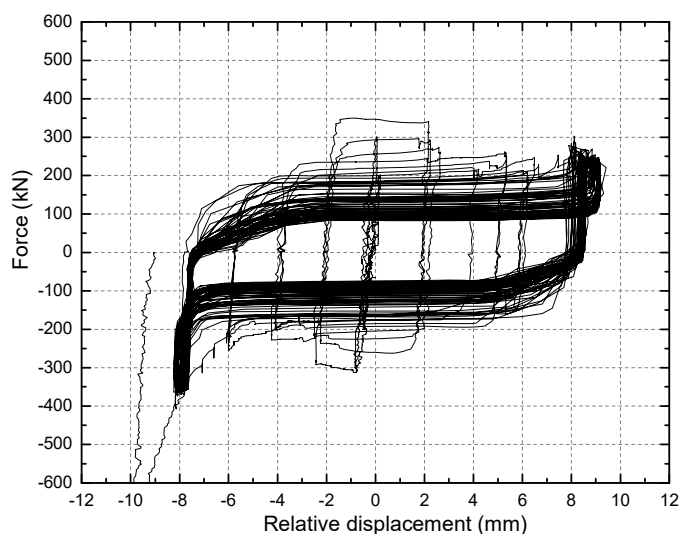

(f) $\mathrm{S} 1-3\left(130^{\circ} \mathrm{C}\right)$

Figure 10. Comparison of Force-slip Displacement Curves of Specimens S1 with M20 bolts at Different Temperatures

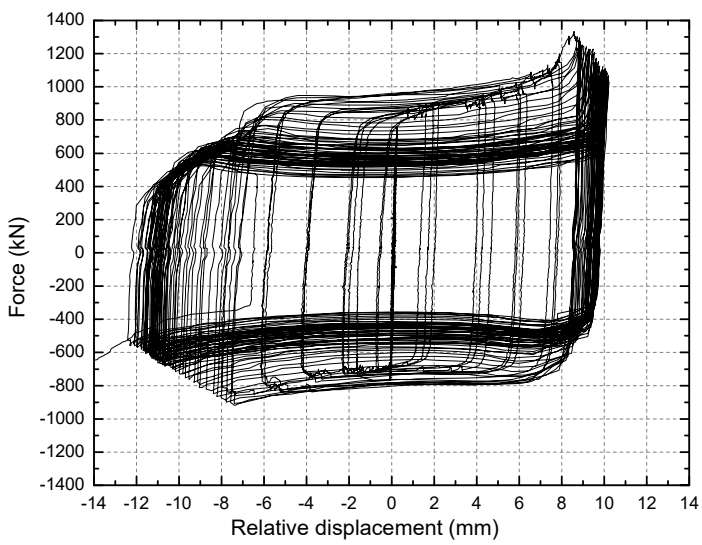

(a) $\mathrm{S} 2-1\left(20^{\circ} \mathrm{C}\right)$

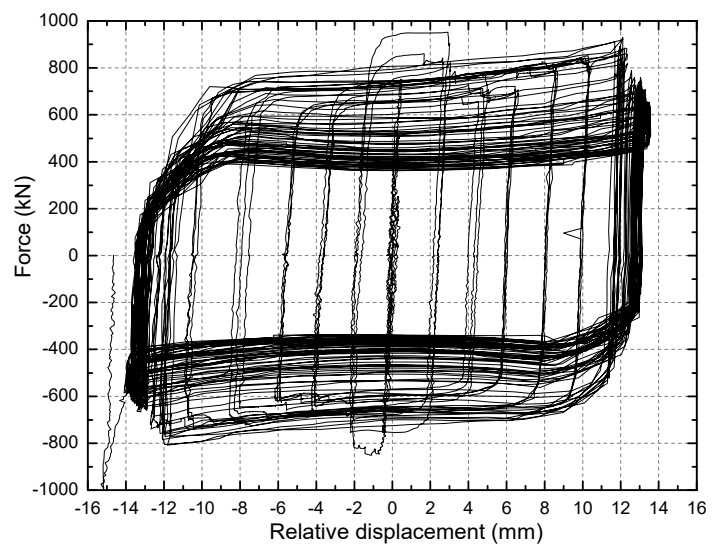

(b) $\mathrm{S} 2-1\left(130^{\circ} \mathrm{C}\right)$ 


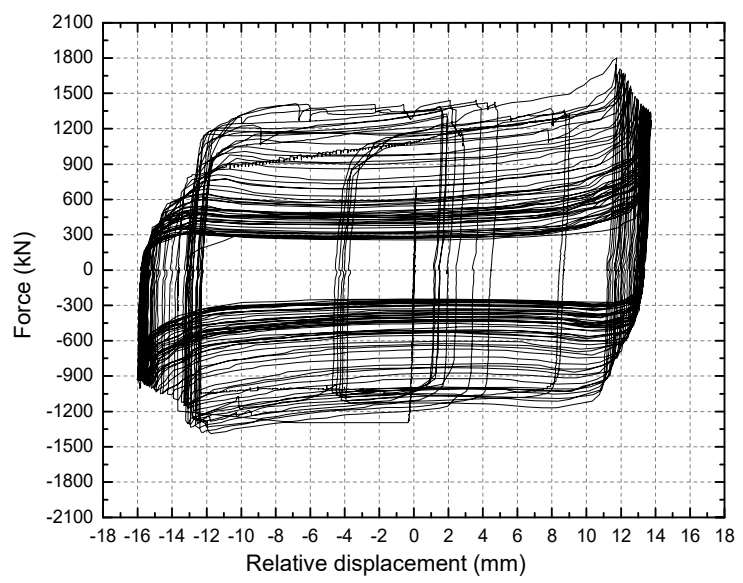

(c) $\mathrm{S} 2-2\left(20^{\circ} \mathrm{C}\right)$

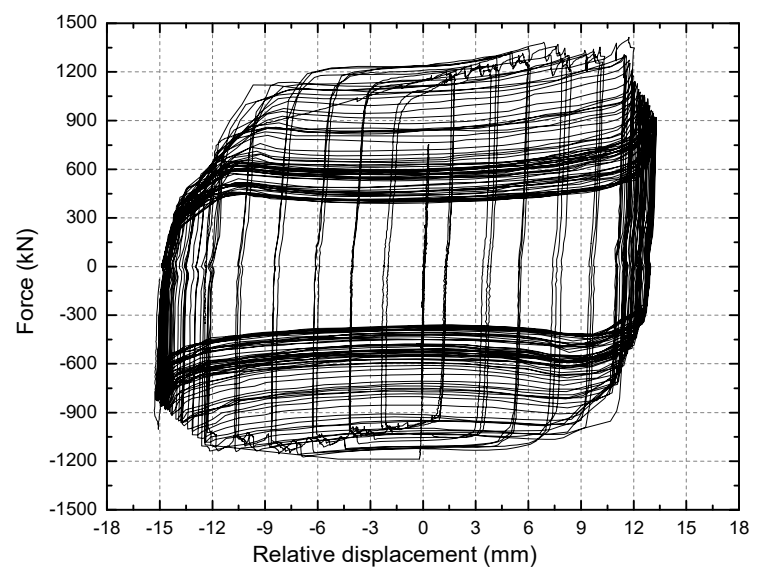

(e) $\mathrm{S} 2-3\left(20^{\circ} \mathrm{C}\right)$

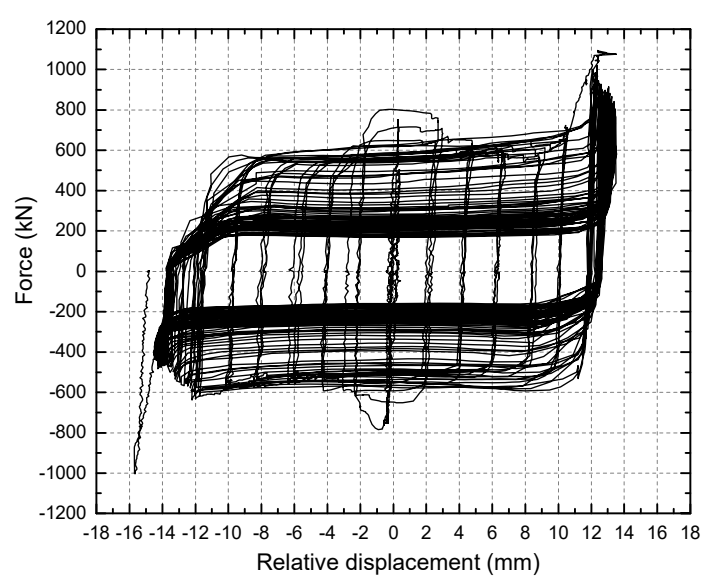

(d) $\mathrm{S} 2-2\left(130^{\circ} \mathrm{C}\right)$

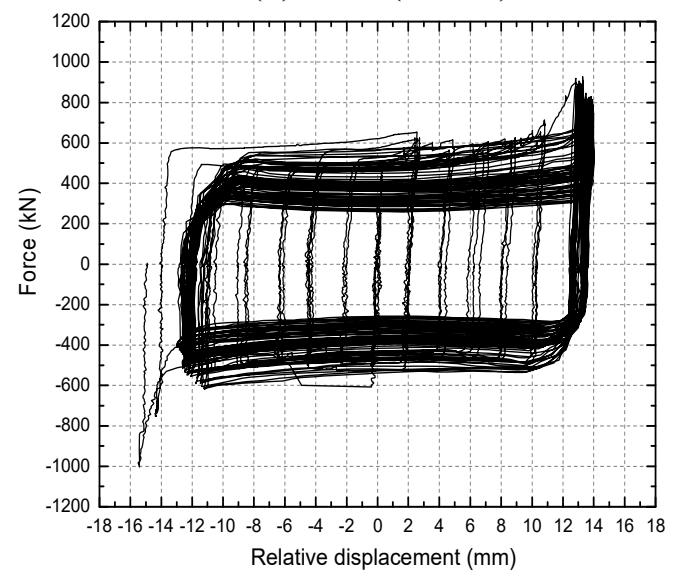

(f) $\mathrm{S} 2-3\left(130^{\circ} \mathrm{C}\right)$

Figure 11. Comparison of Force-slip Displacement Curves of Specimens S2 with M30 Bolts at Different Temperatures

There was no obvious deformation of bolts at ambient and elevated temperatures. The deformation of holes for the specimens S1 (M20 bolts) and S2 (M30 bolts) after test was shown in Figures 12 and 13, respectively. It was found that the holes for M20 bolts deformed due to the contact between the bolt and hole. This deformation effect was less significant in the holes for M30 bolts. Both specimens showed obvious sliding distances which is helpful for dissipating seismic energy.

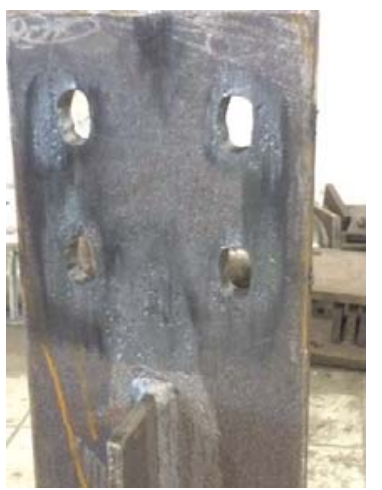

(a) at ambient temperatures

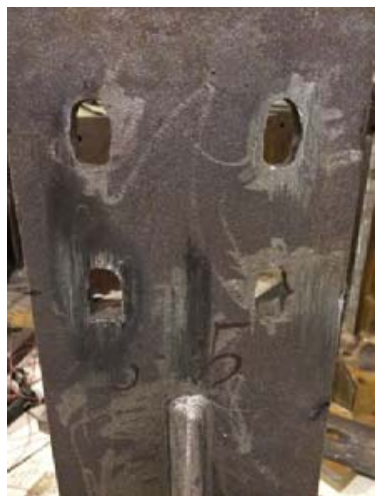

(b) at elevated temperatures

Figure 12. Deformation of Holes for M20 Bolts after Test 


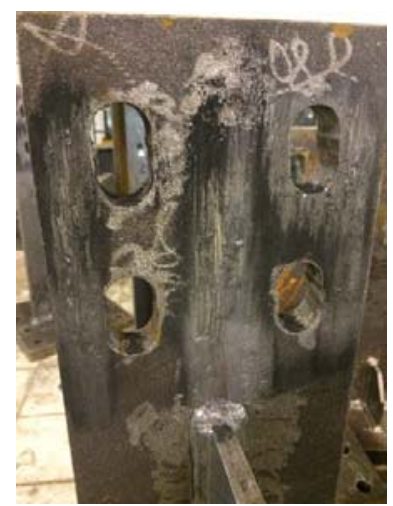

(a) at ambient temperatures

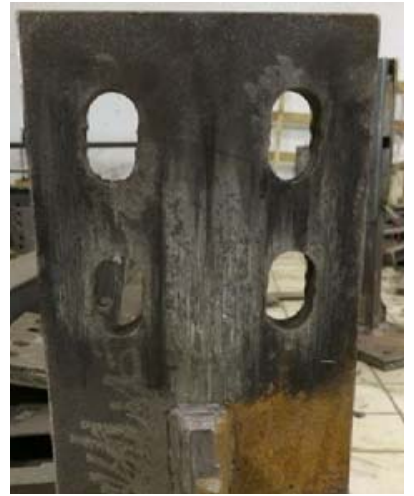

(b) at elevated temperatures

Figure 13. Deformation of Holes for M30 Bolts after Test

To quantitatively investigate the variation of hysteresis loops against number of loops, the hysteresis curves for the 1st, 30th and 60th loops were compared, as shown in Figures 14 and 15. There are some common features that the sliding load decreased more in the first 30 loops compared with the latter 30 loops. The decrease of sliding load may be due to that the friction surface tended to be smooth and the coefficient of friction decreased. After the first 30 loops of sliding, the smoothness of the friction surface became stable and thus there was no significant reduction in the sliding force for the latter 30 loops. This explanation was consistent with the continuous sound in first 30 loops and less sound in the latter 30 loops. During the experiments, the screw constantly impacted the hole wall causing the hole wall deformation which was more obvious in the first 30 loops. The effect of temperature lies in the rate of decay of friction. It was found in Figures 14 and 15 that the drop of sliding force at elevated temperatures was much smaller than that at ambient temperature. This means the elevated temperature increases the stability of the friction coefficient.

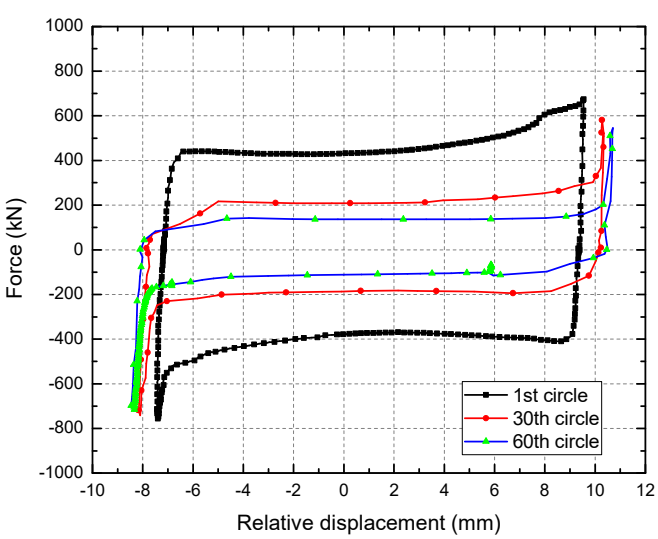

(a) $\mathrm{S} 1-1\left(20^{\circ} \mathrm{C}\right)$

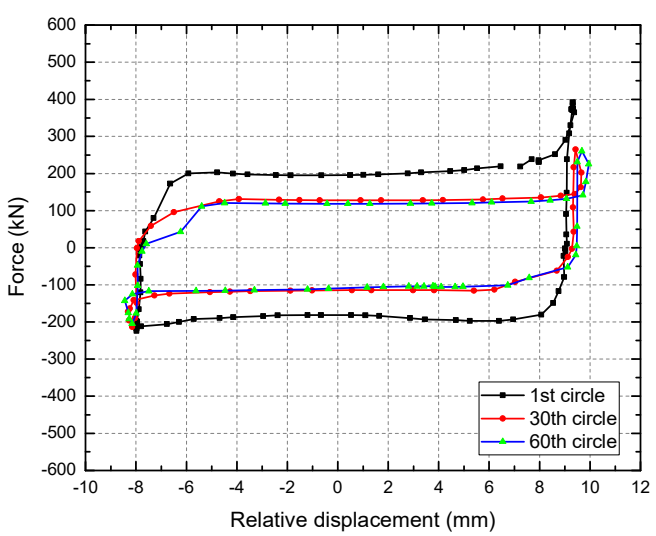

(b) $\mathrm{S} 1-1\left(130^{\circ} \mathrm{C}\right)$ 


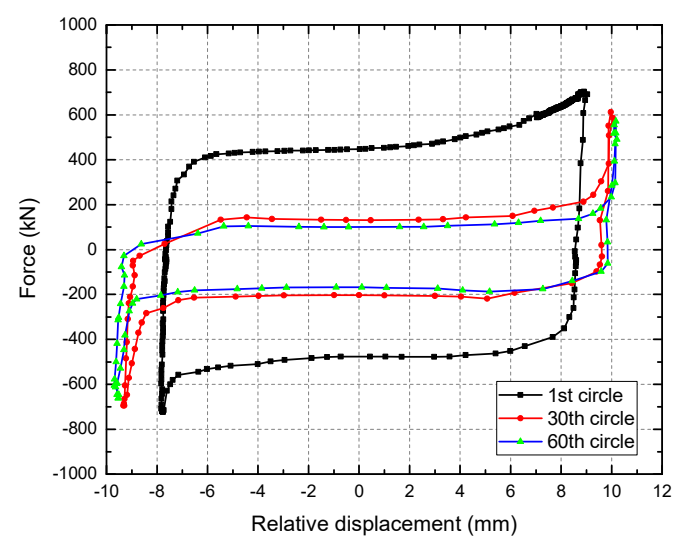

(c) $\mathrm{S} 1-2\left(20^{\circ} \mathrm{C}\right)$

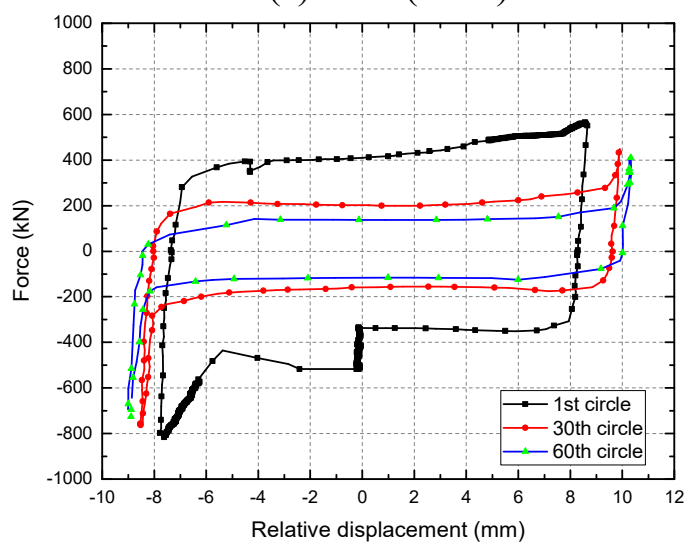

(e) $\mathrm{S} 1-3\left(20^{\circ} \mathrm{C}\right)$

Figure 14. Comparison of Three Hysteresis Loops of Specimens S1 with M20 Bolts at Different Temperatures

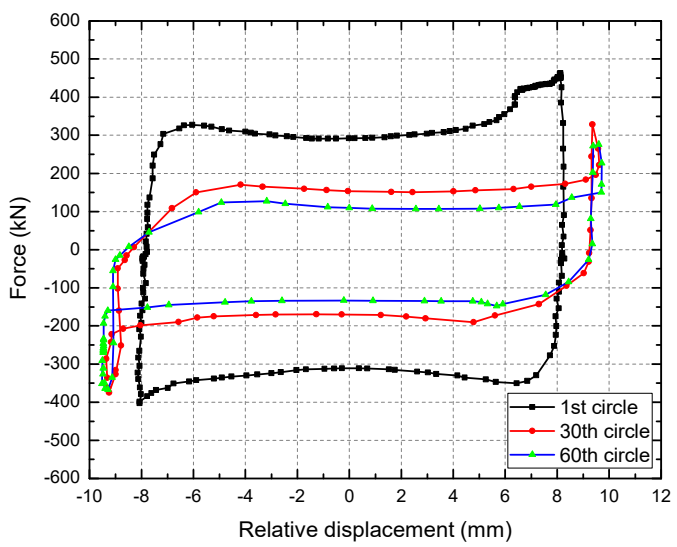

(d) $\mathrm{S} 1-2\left(130^{\circ} \mathrm{C}\right)$

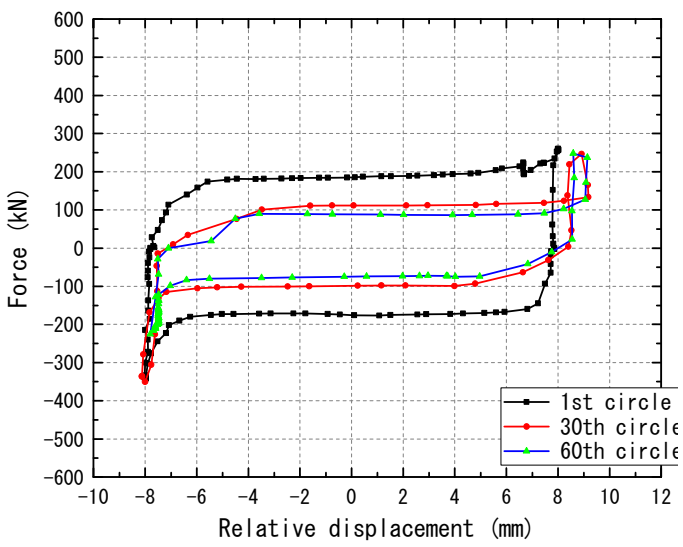

(f) $\mathrm{S} 1-3\left(130^{\circ} \mathrm{C}\right)$

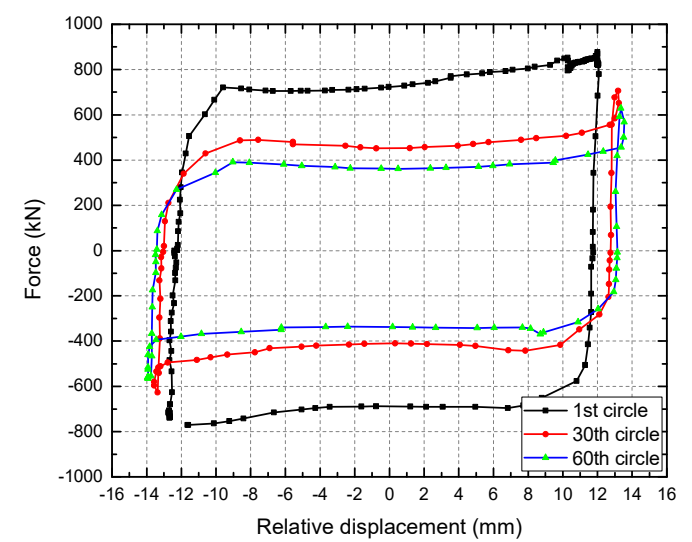

(b) $\mathrm{S} 2-1\left(130^{\circ} \mathrm{C}\right)$

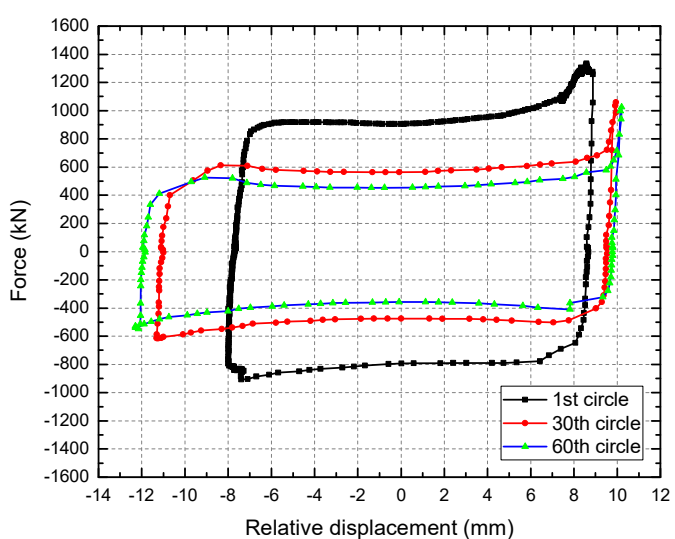

(a) $\mathrm{S} 2-1\left(20^{\circ} \mathrm{C}\right)$ 


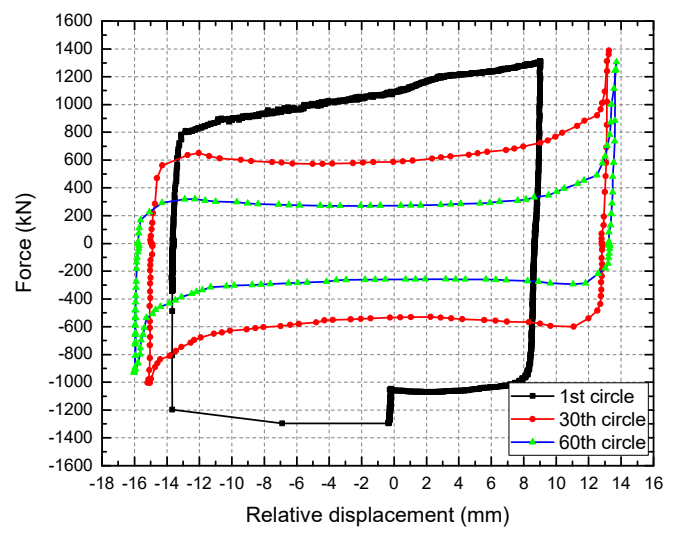

(c) $\mathrm{S} 2-2\left(20^{\circ} \mathrm{C}\right)$

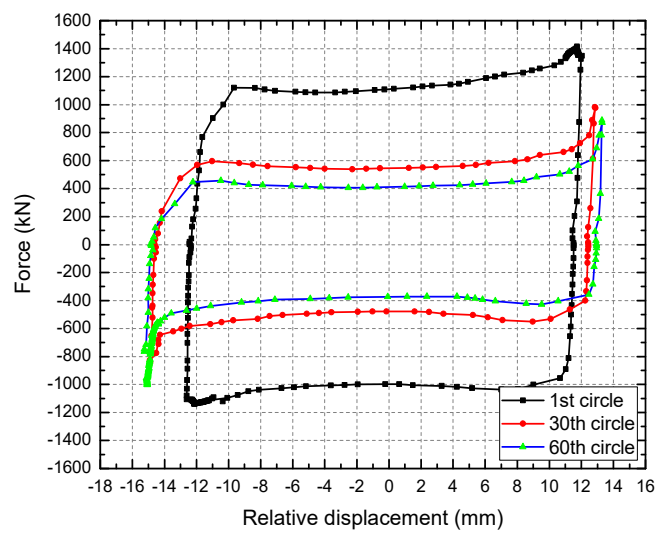

(e) $\mathrm{S} 2-3\left(20^{\circ} \mathrm{C}\right)$

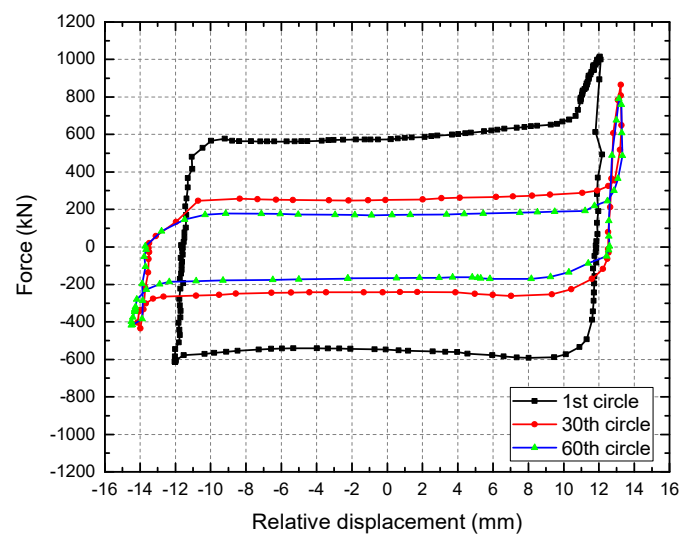

(d) $\mathrm{S} 2-2\left(130^{\circ} \mathrm{C}\right)$

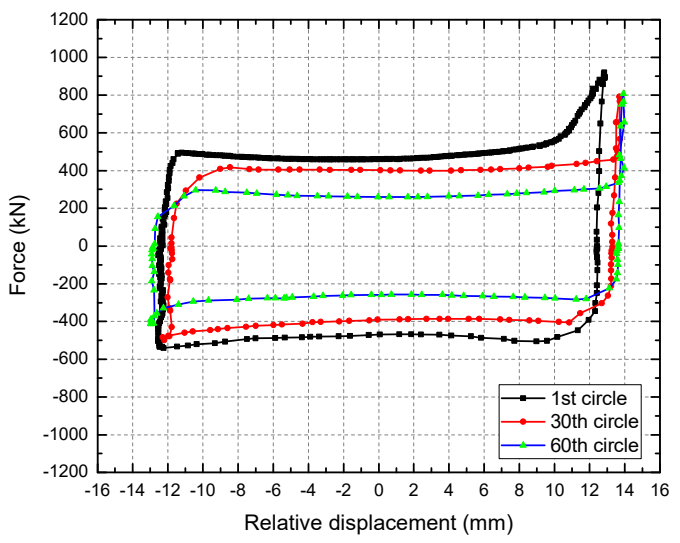

(f) $\mathrm{S} 2-3\left(130^{\circ} \mathrm{C}\right)$

Figure 15. Comparison of Three Hysteresis Loops of Specimens S2 with M30 bolts at Different Temperatures

Tables 2 and 3 list the sliding forces of specimens at ambient and elevated temperature, respectively. The average results of the three specimens for S1 and S2 were calculated, respectively. Table 2 showed that, after the first 30 loops, the sliding force decreased by more than $50 \%$ for both M20 and M30 bolts, while it decreased by more than $65 \%$ after 60 loops. The reduction of sliding forces for the M20 bolts was greater than that for the M30 bolts. This indicates that the M30 bolts have a better load-bearing capacity under cyclic loads. For the connections at elevated temperature (Table 3), the reduction of sliding forces was smaller than that at ambient temperature. This may be due to the fact that the pretension in the bolts increased as the temperature increased.

Table 2. Sliding Force of the Specimens against Number of Loops at Ambient Temperatures $\left(20^{\circ} \mathrm{C}\right)$

\begin{tabular}{|c|c|c|c|c|c|c|c|}
\hline \multirow{2}{*}{ Specimen } & \multirow{2}{*}{ Bolt } & \begin{tabular}{c} 
Design \\
Value \\
\cline { 5 - 8 }
\end{tabular} & & \multicolumn{5}{|c|}{ Measured value (kN) } \\
\cline { 5 - 8 } & Fs1 & Fs30 & $($ Fs1-Fs30)/Fs1 & Fs60 & $($ Fs1-Fs60)/Fs1 \\
\hline S1 & M20 & 372 & 418 & 198 & $53 \%$ & 120 & $71 \%$ \\
\hline S2 & M30 & 852 & 1074 & 567 & $47 \%$ & 377 & $65 \%$ \\
\hline
\end{tabular}


Table 3. Sliding Forces of the Specimens against Number of Loops at Elevated Temperatures $\left(130^{\circ} \mathrm{C}\right)$

\begin{tabular}{|c|c|c|c|c|c|c|c|}
\hline \multirow{2}{*}{ Specimen } & \multirow{2}{*}{ Bolt } & \multirow{2}{*}{\begin{tabular}{c} 
Design \\
Value \\
\cline { 5 - 8 }
\end{tabular}} & & \multicolumn{5}{|c|}{ Measured value (kN) } \\
\cline { 5 - 8 } & Fs1 & Fs30 & $($ Fs1-Fs30)/Fs1 & Fs60 & $($ Fs1-Fs60)/Fs1 \\
\hline S1 & M20 & 372 & 225 & 132 & $41 \%$ & 106 & $53 \%$ \\
\hline S2 & M30 & 852 & 586 & 368 & $37 \%$ & 264 & $55 \%$ \\
\hline
\end{tabular}

\subsection{Fatigue Property}

To clearly reflect the energy dissipation capacity and friction coefficients of the tested connections, the relationship between them and the number of cyclic loading loops were expressed in Figures 16 and 17. The "force ratio" represents the ratio of the external force to the sliding force when the displacement became zero. Similarly, the "area ratio" represents the ratio of the hysteresis loop area enclosed by each loop to that of the first loop. The force ratios for the pushing and pulling loading process were presented. As shown in Figures 16 and 17, the hysteretic curve area and surface friction coefficient decreased with the increase of loading loops in a similar trend. The similar trend may be due to the fact that the energy consumption of high strength bolt connections with slot holes mainly depended on the friction of the surfaces.

The friction coefficient and the area of the hysteresis curve decreased by about $40 \%$ after the first 30 loops. After 60 loops, the reduction ratio of M20 bolt connections and M30 bolts connections dropped to $40 \%$ and $50 \%$ of the initial values, respectively. Therefore, the connection with M30 bolts had a better energy dissipation capacity and fatigue performance.

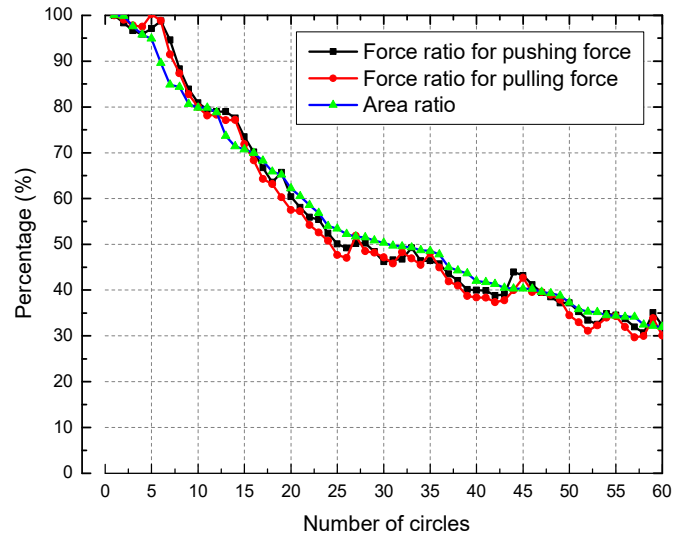

(a) $\mathrm{S} 1-1\left(20^{\circ} \mathrm{C}\right)$

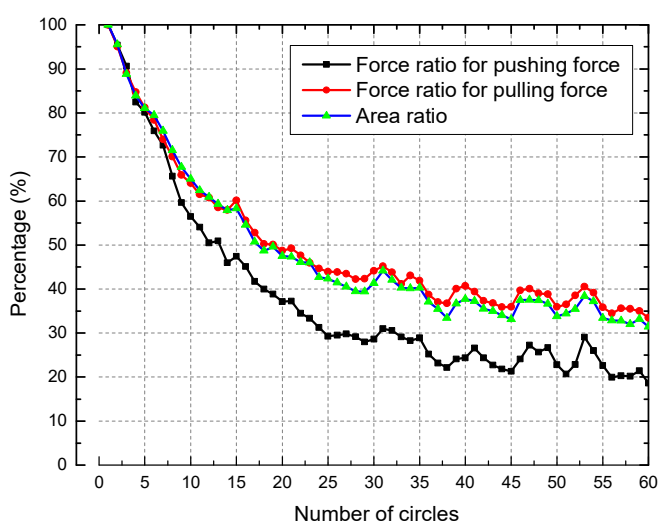

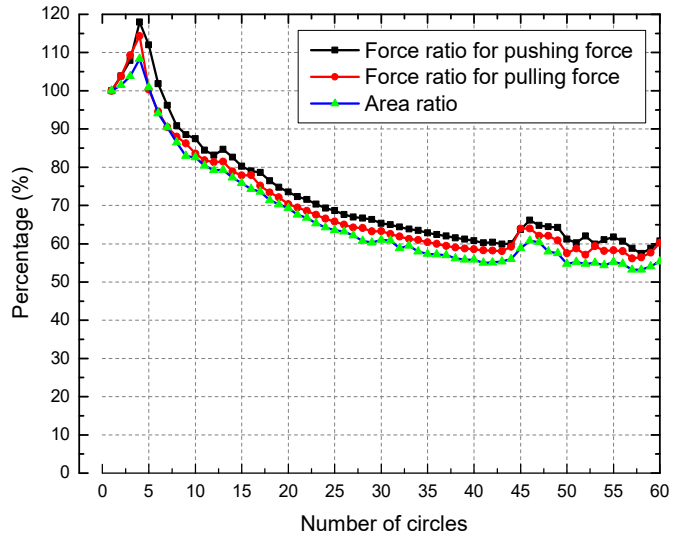

(b) $\mathrm{S} 1-1\left(130^{\circ} \mathrm{C}\right)$

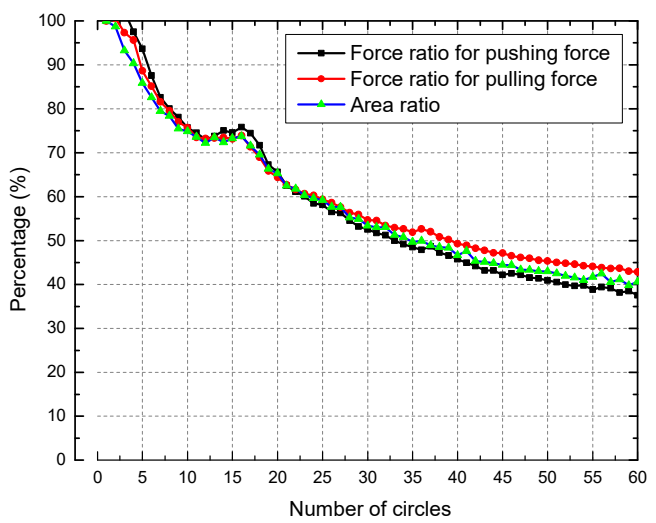


(c) $\mathrm{S} 1-2\left(20^{\circ} \mathrm{C}\right)$

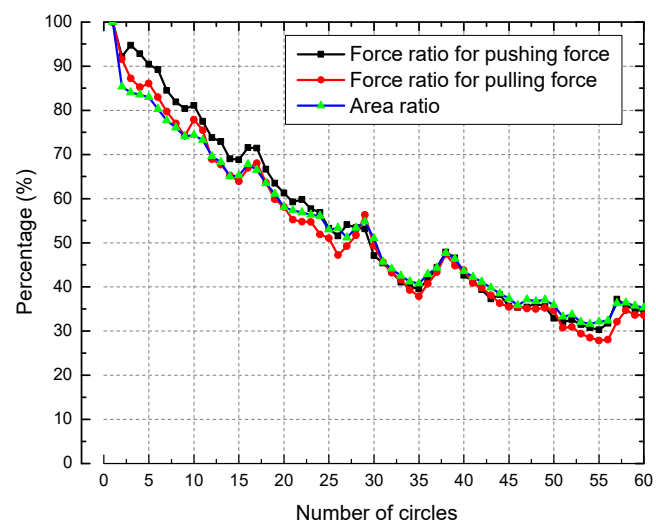

(e) $\mathrm{S} 1-3\left(20^{\circ} \mathrm{C}\right)$ (d) $\mathrm{S} 1-2\left(130^{\circ} \mathrm{C}\right)$

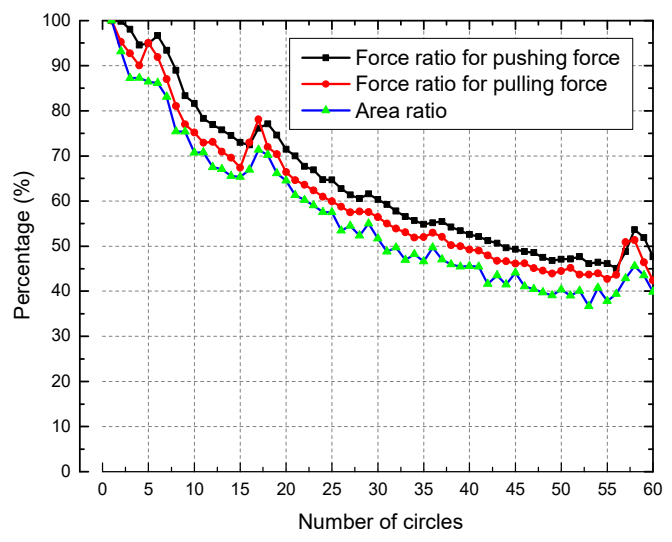

(f) $\mathrm{S} 1-3\left(130^{\circ} \mathrm{C}\right)$

Figure 16. Relation between the Energy Dissipation Capacity and Friction Coefficients of the Tested Connections S1 and the Number of Loading Loops

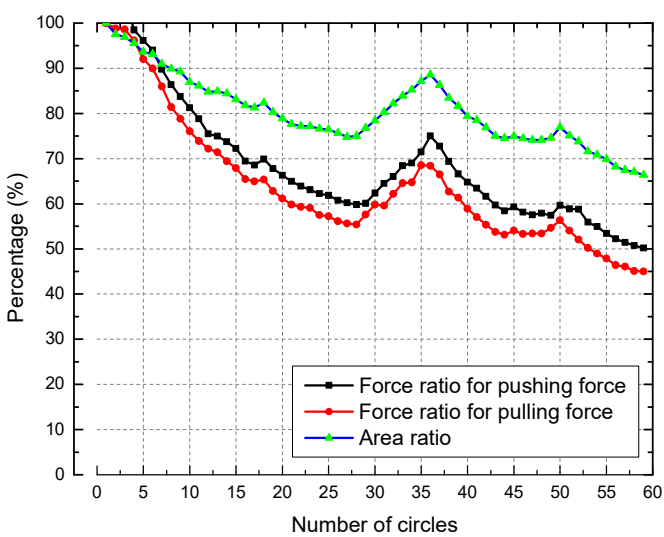

(a) $\mathrm{S} 2-1\left(20^{\circ} \mathrm{C}\right)$

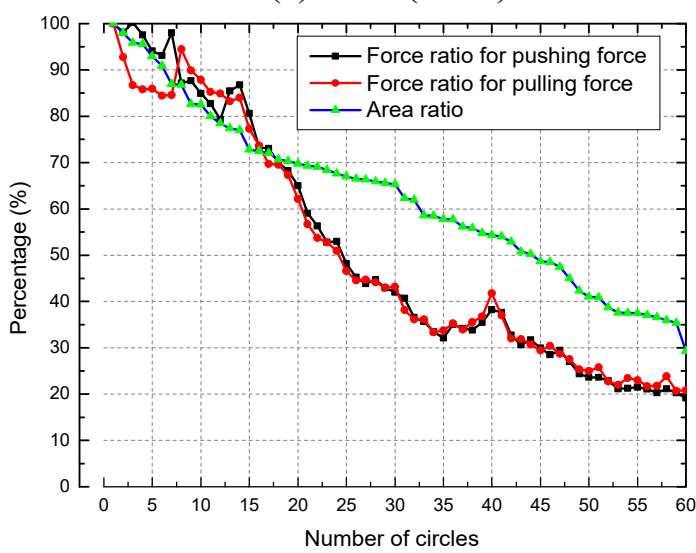

(c) $\mathrm{S} 2-2\left(20^{\circ} \mathrm{C}\right)$

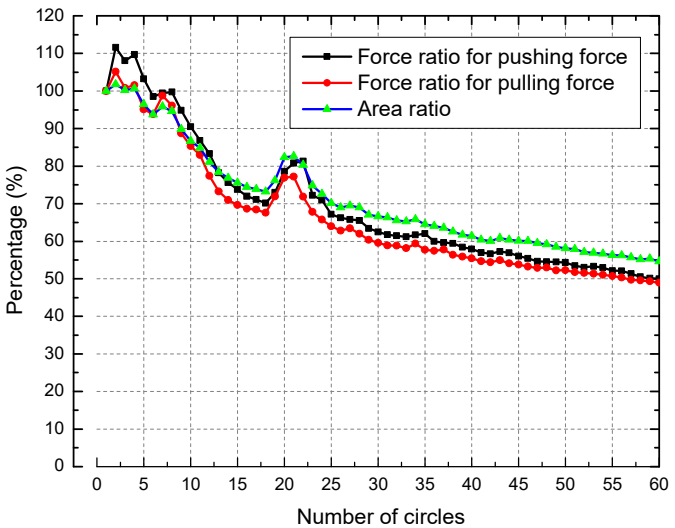

(b) $\mathrm{S} 2-1\left(130^{\circ} \mathrm{C}\right)$

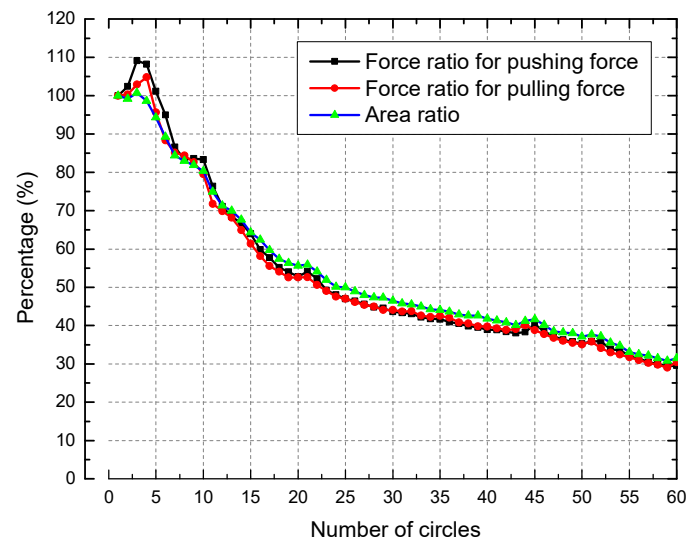

(d) $\mathrm{S} 2-2\left(130^{\circ} \mathrm{C}\right)$ 


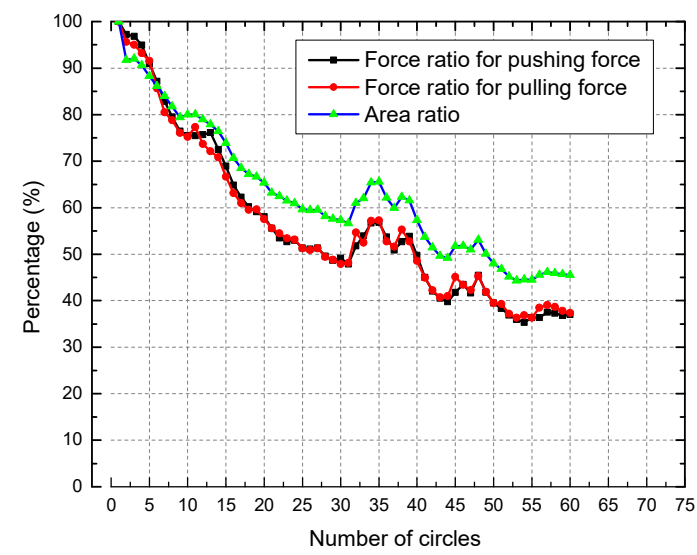

(e) $\mathrm{S} 2-3\left(20^{\circ} \mathrm{C}\right)$

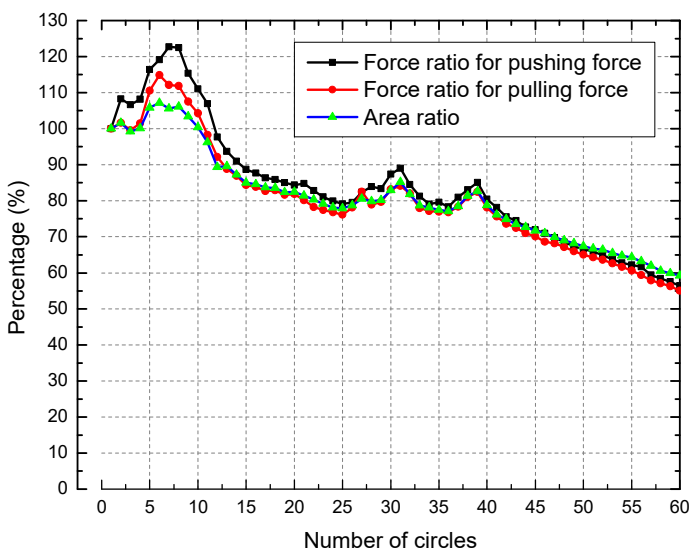

(f) $\mathrm{S} 2-3\left(130^{\circ} \mathrm{C}\right)$

Figure 17. Relation between the Energy Dissipation Capacity and Friction Coefficients of the Tested Connections S2 and the Number of Loading Loops

Compared with the experiments results at ambient temperature, the energy consumption of high strength bolt connections at $130^{\circ} \mathrm{C}$ increased by about $10 \%$ of its initial value, which was consistent with the conclusion that the friction coefficient increased as the temperature increased, which determined the capacity of dissipating earthquake energy.

\section{CONCLUSIONS}

This paper experimentally studied the seismic behavior of high strength bolted connections with slot holes at ambient and elevated temperatures. The following conclusions can be drawn:

(1) High strength bolt connections with slot holes had full hysteretic loops and thus good energy dissipation capacity at both ambient and elevated temperatures.

(2) It was found that connections with M30 bolts had better energy dissipation capacity and load-bearing capacity than those with M20 bolts. This is because that the M30 bolts had a larger pretention and wider slot hole compared to M20 bolts, which lead to larger friction forces and sliding distances.

(3) The sliding forces of the connections decreased with the increase of the number of loops, and the hysteresis curves had a slight tendency of pinching. The sliding force reduced by about $50 \%$ after 60 loops at elevated temperature, compared with 35\% at ambient temperature.

(4) The ultimate bearing capacity of the connections did not decrease much with the increase of the number of loading loops.

(5) The friction coefficient and the area of the hysteresis curve decreased by $40 \%$ after the first 30 loops. After 60 loops, the reduction ratio of connections with M20 bolts and M30 bolts dropped to $40 \%$ and $50 \%$ of their initial values, respectively.

The experimental results showed that the bolted connections with slot holes had good energy dissipation capacity at both ambient and elevated temperatures. They can be used as a friction damper by dissipating energy through the friction of plate surfaces. This type of connections can also provide both bearing capacity and stiffness before sliding. This means the connection with slot holes can be used as a dual-function component in a structure to provide stiffness and energy 
dissipation at the same time. However, the large decrease of bearing capacity along with sliding should be avoided by improving the property of friction surfaces. The use of paint on the contact surface may be an effective method to enhance the sliding resistance which needs further investigations.

\section{ACKNOWLEDGEMENT}

The work presented in this paper was supported by the National Natural Science Foundation of China with Grants 51408418, 51120185001 and 51508412. This work was also supported by the Ministry of Science and Technology of China with Grant SLDRCE14-A-05, and Natural Science Foundation of Tianjin 16JCQNJC07000.

\section{REFERENCES}

[1] Shi, G., Wang, M., Wang, Y.Q. and Wang, F., "Cyclic Behavior of 460MPa High Strength Structural Steel and Welded Connection under Earthquake Loading", Advances in Structural Engineering, 2013, Vol. 16, No. 3, pp. 451-462.

[2] Mille, D.K., "Lessons Learned from the Northridge Earthquake", Engineering Structures, 1998, Vol. 20, No. 4, pp. 249-260.

[3] Engelhardt, M.D. and Sabol, T.A., "Test of Steel Moment Resist Connections in Response to Earthquake", Program Report to the AISC Advisory Subcommittee on Special Moment Resisting Frame Research, Oct.1994.

[4] Jayachandran, S., Marimuthu, V., Prabha, P., Seetharaman, S. and Pandian, N., "Investigations on the Behaviour of Semi-rigid Endplate Connections", Advanced Steel Construction, 2009, Vol. 5, No. 4, pp. 432-451.

[5] Qin, Y., Chen, Z. and Wang, X., "Seismic Behavior of Through-diaphragm Connections between CFRT Columns and Steel Beams-experimental Study", Advanced Steel Construction, 2014, Vol. 10, No. 3, pp. 351-371.

[6] Henriques J., Jaspart J.P. and Simões da Silva L., "Ductility Requirements for the Design of Bolted Lap Shear Connections in Bearing", Advanced Steel Construction, 2014, Vol. 10, No. 1, pp. 33-52.

[7] Bernuzzi, C., Calado, L. and Castiglioni, C.A., "Behaviour of Steel Beam-to-column Joints under Cyclic Reversal Loading: An Experimental Study", Proceedings of 5th Int. Coll. on Stability and Ductility of Steel Structures, SDSS, Nagoya, 1997, Vol. 1, pp. 335-342.

[8] ASTANEH-Asl, A., "Seismic Design of Steel Column-tree Moment-resisting Frames", Steel Tips, Structural Steel Educational Council, Moraga, CA, 1997.

[9] Grigorian, C.E., Yang, T.S. and Popov, E.P., "Slotted Bolted Connections for Energy Dissipators", College of Engineering University of California at Berleley, 1992.

[10] Zhao, X.M. and Ha, K.H., "Friction Connection for Seismic Control of Moment Resisting Steel Frame", Proceedings of 11th World Conference on Earthquake Engineering,1996, pp. 1963.

[11] Way, D. and Loh, E., "Friction-Damped Moment Frame", Proceedings of 11th World Conference on Earthquake Engineering, 1996, pp. 19.

[12] John, J.W. and Charles, G.C., "Performance of Hierarchical Friction Dissipating Joints in Moment Resisting Steel Frame", Proceedings of 11thWorld Conference on Earthquake Engineering, 2000, pp. 718.

[13] Peng, T.H., Hou, Z.X., Wen, S.L. and Gao, J.Z., "Experiment on Effect of Hole Size and Hole Shape on Bearing Capacity of High Strength Bolt Friction Type Connection", Steel Construction, 2007, Vol. 8, No. 22, pp.30-34. 
[14] ANSI/AISC360-10. Specification for Structural Steel Buildings, American Institute of Steel Construction, 2010.

[15] Eurocode 3: Design of Steel Structures: Part 1. General Requirements, European Committee for Standardization, 1992.

[16] Ronald, N.A., "The Effect of Over Size and Slotted Holes on the Behavior of a Bolted Joint", PhD Thesis, Lehigh University, 1967.

[17] Li, G.Q. and Wang, P.J., "Advanced Analysis and Design for Fire Safety of Steel Structures", Zhejiang: Zhejiang University Press, 2013, pp. 43-48.

[18] Yang, K.C., Hsu, R.J. and Chen, Y.J., "Shear Strength of High-strength Bolts at Elevated Temperature", Construction and Building Materials, 2011, Vol. 25, pp. 3656-3660.

[19] Yu, L., "Behavior of Bolted Connections during and after a Fire", PhD Thesis, The University of Texas at Austin, 2006.

[20] Braxtan, N.L. and Pessiki, S.P., "Postearthquake Fire Performance of Sprayed Fire-Resistive Material on Steel Moment Frames”, Journal of Structural Engineering, 2011, Vol. 137, No. 9, pp. 946-953.

[21] Corte, G.D., Landolfo, R. and Mazzolani, F.M., "Post-earthquake Fire Resistance of Moment Resisting Steel Frames", Fire Safety Journal, 2003, Vol. 38, No. 7, pp. 593-612.

[22] Pucinotti, R., Bursi, O.S. and Franssen, J.M., "Seismic-induced Fire Resistance of Composite Welded Beam-to-column Joints with Concrete-filled Tubes", Fire Safety Journal, 2011, Vol. 46, No. 6, pp. 335-347.

[23] Kamath, P., Sharma, U.K. and Kumar, V., "Full-scale Fire Test on an Earthquake-damaged Reinforced Concrete Frame”, Fire Safety Journal, 2015, Vol. 73, pp. 1-19.

[24] Wen, B., Wu, B. and Niu, D., "Post-earthquake Fire Performance of Reinforced Concrete Columns", Structure and Infrastructure Engineering, 2015, Vol. 12, No. 9, pp. 1-21. 